\title{
Genetic differentiation among populations of Myopus schisticolor (the wood lemming) - isozyme variation
}

\author{
VADIM B. FEDOROV †, RICKARD FREDRIKSSON $\ddagger \&$ KARL FREDGA $\ddagger^{*}$ \\ $\dagger$ Institute of Plant and Animal Ecology, Russian Academy of Sciences, 8 March Street 202, Jekaterinburg 620008 , \\ Russia and $\ddagger$ Department of Genetics, Uppsala University, Box 7003, S-750 07 Uppsala, Sweden
}

\begin{abstract}
To investigate genetic differentiation among populations of the wood lemming Myopus schisticolor (Muridae, Rodentia) isozyme variation in 10 populations from three regions, Fennoscandia, Western and Eastern Siberia, was examined. From 20 loci examined, the two most polymorphic ones, Idh-1 and Pgi-1, were used in the complete survey. The results of hierarchical $F$-statistics analysis showed significant differentiation among all populations; single locus $F_{\mathrm{PT}}$ values agreed well $\left(I d h-1, F_{\mathrm{PT}}=0.20 ;\right.$ Pgi-1, $\left.F_{\mathrm{PT}}=0.20\right)$. However, allele frequencies at each locus demonstrated different patterns of subdivision among populations within regions and between regions. Thus, significant values of $F$-statistics within $\left(F_{\mathrm{PR}}=0.10\right)$ and between $\left(F_{\mathrm{RT}}=0.10\right)$ regions were found at Idh-1. Pgi-1 showed no significant differentiation among populations within regions $\left(F_{\mathrm{PR}}=0.01\right)$. The subdivision among populations at $P g i-1$ was based on differentiation between regions $\left(F_{\mathrm{RT}}=0.19\right)$. The lack of differentiation among populations within a geographical region at the Pgi1 locus is surprising for any rodent species, and the discrepancy between single-locus patterns of subdivision seems likely to result from selection at the Pgi-1 locus.
\end{abstract}

Keywords: F-statistics, genetic differentiation, isozymes, Myopus schisticolor, phosphoglucose isomerase, selection.

\section{Introduction}

The patterns of genetic differentiation of populations are important for understanding microevolution (Slatkin, 1987). Protein electrophoresis has been widely used to describe genetic structure within populations of rodent species while there are only a few estimations of population differentiation at the macrogeographical level (Wright, 1978; Chesser, 1983; Navajias-Navarro \& Britton-Davidian, 1989; Patton \& Smith, 1990).

The wood lemming Myopus schisticolor has drawn the attention of evolutionary biologists in recent years. It has an unusual genetic system of sex determination which, among other effects, leads to a skewed sex ratio (Fredga et al., 1976, 1977). Besides this, the wood lemming has an extremely wide geographical distribution from Norway through most of the Eurasian coniferous forest zone to Kamchatka (Fig. 1), and it exhibits dramatic fluctuations in population size. Both a female-biased sex ratio and fluctuations in density lead to a reduction in effective population size, $N_{\mathrm{e}}$.

${ }^{*}$ Correspondence.
Therefore a high degree of differentiation among populations over long geographical distances could be expected both through genetic drift and through natural selection to environmental variation.

The low genetic variation within wood lemming populations from Western Siberia and Scandinavia has been reported previously (Fedorov, 1990; Fredga et al., 1993). In this paper we examine isozyme variability among wood lemming populations over a wide geographical area from Scandinavia to Eastern Siberia.

\section{Materials and methods}

In 1984-1991 wood lemmings were collected in the following 10 localities from what we consider as different populations (Fig. 1).

1. Risberget, Southeast Norway.

2. Varaldskogen, Southeast Norway.

3. Hällefors, Central Sweden.

4. Garpenberg, Central Sweden.

5. Kungsberget, Central Sweden.

6. Sotkamo, Central Finland.

7. Malay Sosva Reserve, Western Siberia, Russia. 


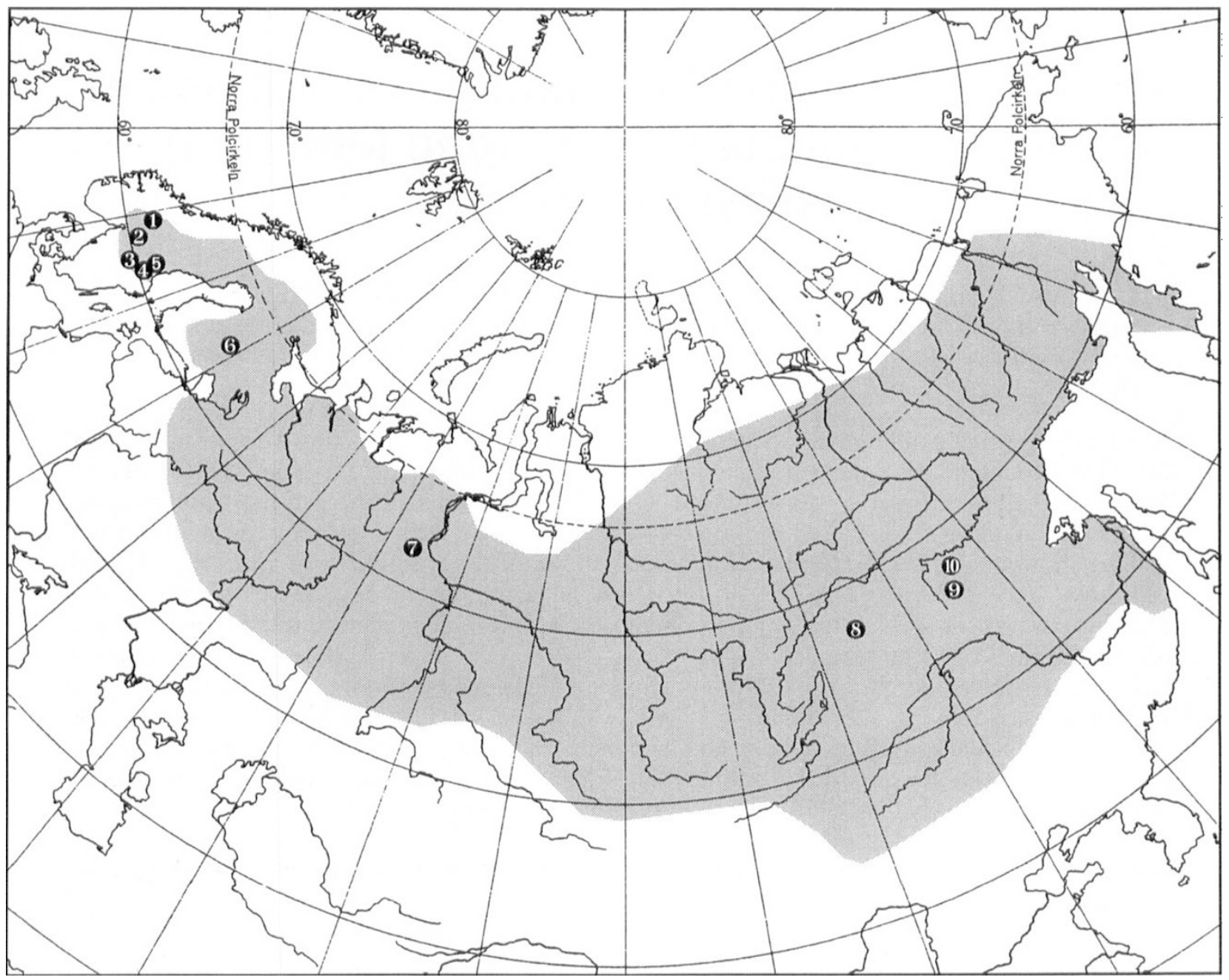

Fig. 1 Worldwide distribution of the wood lemming, Myopus schisticolor, also indicating the location of the 10 investigated populations. The numbers refer to localities given in 'Materials and methods'. (Distribution partly based on Gorbunov \& Kulik,
1974.)

8. Chara, Northern Zabaikalye, Eastern Siberia, Russia.

9. Chulman, Southern Jakutia, Eastern Siberia, Russia.

10. Chulmakan, Southern Jakutia, Eastern Siberia, Russia.

The methods of lemming trapping and the design of the field study were described earlier (Gileva \& Fedorov, 1991; Bondrup-Neilsen et al., 1993). Numbers of lemmings sampled are given in Table 1 . Allele frequencies in some of the populations $(1-3$, 7-8) have been published elsewhere (Fredga et al., 1993; Fedorov, 1993).

\section{Electrophoresis}

Genetic differentiation among populations was studied by means of isozyme electrophoresis using horizontal starch gel electrophoresis. The laboratory methods and the genetic interpretation of the isozyme variation were described by Fedorov (1990) and Fredga et al. (1993).

We examined the following 13 enzymes, representing a total of 20 protein loci: aspartate aminotransferase (AAT, E.C. 2.6.1.1: Aat-1, Aat-2), isocitrate dehydrogenase (IDH, E.C. 1.1.1.42: Idh-1, Idh-2), lactate dehydrogenase (LDH, E.C. 1.1.1.27: $L d h-1$, Ldh-2), malate dehydrogenase (MDH, E.C. 1.1.1.37: 
Table 1 Allele frequencies for two polymorphic loci $(I d h-1$ and $P g i-1)$ in 10 populations of the wood lemming, Myopus schisticolor

\begin{tabular}{|c|c|c|c|c|c|c|c|c|c|c|}
\hline \multirow[b]{2}{*}{ Locus } & \multicolumn{10}{|c|}{ Population number } \\
\hline & 1 & 2 & 3 & 4 & 5 & 6 & 7 & 8 & 9 & 10 \\
\hline \\
\hline (103) & 0.000 & 0.000 & 0.000 & 0.000 & 0.000 & 0.000 & 0.015 & 0.000 & 0.000 & 0.000 \\
\hline (100) & 0.443 & 0.588 & 0.824 & 0.421 & 0.393 & 0.417 & 0.661 & 0.735 & 1.000 & 1.000 \\
\hline (93) & 0.557 & 0.412 & 0.176 & 0.579 & 0.607 & 0.583 & 0.322 & 0.265 & 0.000 & 0.000 \\
\hline$(n)$ & $(44)$ & (181) & $(37)$ & $(19)$ & (14) & $(6)$ & (446) & $(17)$ & (9) & $(16)$ \\
\hline \multicolumn{11}{|l|}{ Pgi-l } \\
\hline (111) & 0.448 & 0.567 & 0.541 & 0.474 & 0.464 & 0.583 & 0.130 & 0.000 & 0.000 & 0.000 \\
\hline (108) & 0.000 & 0.000 & 0.000 & 0.000 & 0.000 & 0.000 & 0.057 & 0.147 & 0.444 & 0.375 \\
\hline (100) & 0.552 & 0.433 & 0.459 & 0.526 & 0.536 & 0.417 & 0.812 & 0.412 & 0.167 & 0.219 \\
\hline (92) & 0.000 & 0.000 & 0.000 & 0.000 & 0.000 & 0.000 & 0.001 & 0.441 & 0.389 & 0.406 \\
\hline$(n)$ & (29) & (194) & $(37)$ & (19) & (14) & $(6)$ & (446) & $(17)$ & (9) & $(16)$ \\
\hline
\end{tabular}

Sample sizes $(n)$ in parentheses beneath each population.

See Fig. 1 for geographic location of the populations and 'Materials and methods' for name of localities.

Mdh-1, Mdh-2), mannose phosphate isomerase (MPI, E.C. 5.3.8.1: $M p i-1$ ), malic enzyme (ME, E.C. 1.1.1.40: $M e-1, M e-2$ ), aconitase (ACN, E.C. 4.2.1.3: Acn-1, $A c n-2$ ), creatinine kinase (CK, E.C. 2.7.3.2: $C k-1$ ), phosphoglucomutase (PGM, E.C. 2.7.5.1: Pgm-1), phosphoglucose isomerase (PGI, E.C. 5.3.1.9: Pgi-1), superoxide dismutase (SOD, E.C. 1.15.1.1: Sod-1, Sod2), phosphogluconate dehydrogenase (PGDH, E.C. 1.1.1.44: Pgdh-1), sorbitol dehydrogenase (SDH, E.C. 1.1.1.14: $S d h-1)$.

\section{Statistical analysis}

The genotypic data were analysed using the program BIOSYS-1 (Swofford \& Selander, 1981). Significance of deviation from Hardy-Weinberg equilibrium for each population was estimated by using a $\chi^{2}$-test or Fisher's exact test when sample sizes were less than 20 . If significant deviation from equilibrium was found we calculated the fixation index $F_{\text {IS }}$ (Wright, 1978).

To measure genetic subdivision we performed hierarchical analysis of population differentiation (Wright, 1978). All localities were grouped into one of the following three geographical regions (Fig. 1): Fennoscandia (populations 1-6), Western Siberia (population 7) and Eastern Siberia (populations 8-10). The standardized variances of allele frequencies among samples, Wright's $F_{\mathrm{ST}}$, were calculated to quantify the amount of genetic differentiation among populations within regions and between regions. The statistical significance of among-population differentiation was tested by using a $\chi^{2}$-test for heterogeneity of genotypic frequencies at each polymorphic locus. When the expected genotypic frequencies were small, we performed $\chi^{2}$-analysis through Monte Carlo resampling as described by Roff \& Bentzen (1989) using the REAP program (McElroy et al., 1992). An Fstatistic value was considered to be significantly different from zero if statistically significant heterogeneity among localities at the same hierarchical level was found for each locus. To determine the statistical significance of differences between single-locus $F$-statistic values, we used jackknifing over populations, and $t$ tests of jackknifed estimates (Weir, 1990).

Genetic affinities between populations were analysed by estimating pairwise Rogers's (1972) genetic distances which were clustered using the UPGMA method algorithm. The statistical significance of clustering was tested by the jackknife technique (Pamilo et al., 1987). All calculations for the distance analyses were performed using the NTSYS-PC package (Rohlf, 1988), and trees were constructed using the PHYLIP computer package (Felsenstein, 1993).

\section{Results}

\section{Genetic variability}

We examined 387 individuals from 10 localities for all 13 enzymes and the remaining individuals for $I d h-I$ and Pgi-1 only. Of the 20 loci examined, only two (10 per cent) were polymorphic as defined using the 0.95 common allele frequency criterion: Pgi-1 in all 10 populations and $I d h-1$ in eight of the 10 populations. 
Populations 9 and 10 from Southern Jakutia were monomorphic for Idh-1 (Table 1). Two loci, Aat-1 and Mpi-1, showed low polymorphism in the Western Siberian population (7); the frequencies of their common alleles were 0.971 and 0.990 , respectively. Two localities (5 and 7) showed significant departures from Hardy-Weinberg equilibrium. In both populations, there was a deficit of heterozygotes at the Pgi-1 locus: population $5, F_{\mathrm{IS}}=0.569, P<0.039$ and population $7, F_{\mathrm{IS}}=0.106, P<0.004$.

\section{Differentiation among populations}

At first we tested genotype frequency heterogeneity among the 10 populations using Monte Carlo resampling and found significant overall heterogeneity for both Idh-1 $(P<0.001)$ and Pgi-1 $(P<0.001)$. We then subdivided all localities into three macrogeographical regions and tested heterogeneity among localities within Eastern Siberia and within Fennoscandia separately. Western Siberia was excluded because its sample came from a single population. There was significant heterogeneity at the $1 d h-1$ locus among populations both within Eastern Siberia $\left(\chi_{2}^{2}=14.82\right.$, $P<0.001)$ and within Fennoscandia $\left(\chi_{5}^{2}=34.02\right.$, $P<0.001)$. Unlike $I d h-1$, we found no significant heterogeneity at the Pgi-1 locus either between localities within Eastern Siberia $\left(\chi_{4}^{2}=7.91, P>0.05\right)$ or within Fennoscandia $\left(\chi_{5}^{2}=4.51, P>0.05\right)$. Additionally, we pooled genotype frequencies within every region and tested heterogeneity among the three regions. Statistically significant heterogeneity among regions was found for both $I d h-1$ (pooled $\chi_{2}^{2}=38.16$, $\mathrm{P}<0.001)$ and $P g i-1\left(\chi_{6}^{2}=1069.04, P<0.001\right)$.

To measure genetic differentiation, we calculated $F_{\text {ST }}$ values. $F$-statistic estimates among all populations $\left(F_{\mathrm{PT}}\right)$ for both loci were the same (Table 2). However, hierarchical analysis showed considerable difference between Idh-1 and Pgi-I concerning the magnitude of the components of the total estimates. The $F_{\mathrm{PR}}$ value for Pgi-1, measuring differentiation among populations within regions, was not significant $(P>0.05)$. The estimate of the standardized variance of allele frequencies at the Pgi-1 locus between geographical regions $\left(F_{\mathrm{RT}}\right)$ was highly significant. Thus, total subdivision among populations at Pgi-1 was based on differentiation between regions (Table 2 ).

There were significant $F$-statistic values both within and between regions for the $I d h-1$ locus. Total genetic variation between populations at $I d h-1$ was accounted for equally by genetic subdivision within and between regions.

Since jackknifing over populations requires at least five populations (Weir, 1990), we were able to compare the estimates of $F$-statistics for each locus only within Fennoscandia. There was a significant difference between the single-locus (Idh-1 and Pgi-1) $F_{\mathrm{PR}}$ values $\left(t_{10}=2.79, P<0.05\right)$.

\section{UPGMA clustering of populations}

Allele frequencies were used to estimate pairwise genetic distances between populations (Table 3) which were used to cluster the populations. There were two main clusters in the UPGMA dendrograms based on Rogers's distance calculated from the two loci (Fig. 2a).

The jackknife test showed insignificance $(P>0.05)$ of all branching points in the two-locus tree. This instability could be caused by both the small number of loci used and a discrepancy between the two singlelocus estimates of pairwise distances.

The association between single-locus matrices of pairwise genetic distances was tested by using a Mantel test (Manly, 1991). We found no significant correlation $(P>0.05)$. Therefore we constructed single-locus UPGMA trees (jackknife trees) to seek differences in topology. Two main clusters were formed in the tree based on genetic distances from Idh-1 (Fig. 2b). One cluster contained two populations from Southern Jakutia (populations 9 and 10), which were the only ones lacking variation at $I d h-1$ (Table 1). The other main cluster contained the remaining population (8) from Eastern Siberia and all localities from Western Siberia and Fennoscandia. There were considerable differences between the $I d h-1$ tree and the Pgi-1 tree. The tree constructed from Pgi-1 distances showed all Eastern Siberian populations as one main cluster (Fig. 2c). The other main cluster was subdivided into two groups: Fennoscandian populations and the Western Siberian one; the latter region was the only one in which all alleles at the Pgi-1 locus were represented (Table 1). Thus, populations cluster when the Pgi-1 locus is used to calculate genetic distances as would be expected on the basis of their geographical proximity.

Table $2 F$-statistic values among populations of wood lemmings, Myopus schisticolor. Values are given among populations within regions $\left(F_{\mathrm{PR}}\right)$, among regions $\left(F_{\mathrm{RT}}\right)$, and among all populations in total $\left(F_{\mathrm{PT}}\right)$. The table gives significance levels obtained from $\chi^{2}$-tests for allele frequency heterogeneity as described in the text

\begin{tabular}{lllc}
\hline Locus & $F_{\mathrm{PR}}$ & $F_{\mathrm{RT}}$ & $F_{\mathrm{PT}}$ \\
\hline$I d h-1$ & $0.10^{\text {*** }}$ & $0.10^{* * *}$ & $0.20^{* * * *}$ \\
$P g i-1$ & 0.01 & $0.19^{* * *}$ & $0.20^{* * *}$ \\
\hline
\end{tabular}

$* * * P<0.001$. 
Table 3 Genetic distances (Rogers, 1972) between the populations of Myopus schisticolor on the basis of the Idh-1 locus (above the diagonal) and of the Pgi-1 locus (below the diagonal)

\begin{tabular}{|c|c|c|c|c|c|c|c|c|c|c|}
\hline Population & 1 & 2 & 3 & 4 & 5 & 6 & 7 & 8 & 9 & 10 \\
\hline 1 Southeast Norway & - & 0.145 & 0.381 & 0.022 & 0.050 & 0.027 & 0.227 & 0.292 & 0.557 & 0.557 \\
\hline 2 Southeast Norway & 0.119 & - & 0.236 & 0.167 & 0.196 & 0.172 & 0.083 & 0.147 & 0.412 & 0.412 \\
\hline 3 Central Sweden & 0.092 & 0.026 & - & 0.403 & 0.431 & 0.408 & 0.155 & 0.089 & 0.176 & 0.176 \\
\hline 4 Central Sweden & 0.025 & 0.093 & 0.067 & - & 0.028 & 0.004 & 0.249 & 0.314 & 0.579 & 0.579 \\
\hline 5 Central Sweden & 0.016 & 0.103 & 0.076 & 0.009 & - & 0.024 & 0.277 & 0.342 & 0.607 & 0.607 \\
\hline 6 Central Finland & 0.135 & 0.016 & 0.043 & 0.110 & 0.119 & - & 0.254 & 0.319 & 0.583 & 0.583 \\
\hline 7 Western Siberia & 0.293 & 0.411 & 0.385 & 0.318 & 0.309 & 0.427 & - & 0.067 & 0.333 & 0.333 \\
\hline 8 Eastern Siberia & 0.467 & 0.519 & 0.505 & 0.476 & 0.473 & 0.528 & 0.435 & - & 0.265 & 0.265 \\
\hline 9 Eastern Siberia & 0.556 & 0.580 & 0.573 & 0.559 & 0.558 & 0.585 & 0.563 & 0.213 & - & 0.000 \\
\hline 10 Eastern Siberia & 0.591 & 0.609 & 0.603 & 0.593 & 0.592 & 0.613 & 0.606 & 0.275 & 0.063 & - \\
\hline
\end{tabular}

(a)

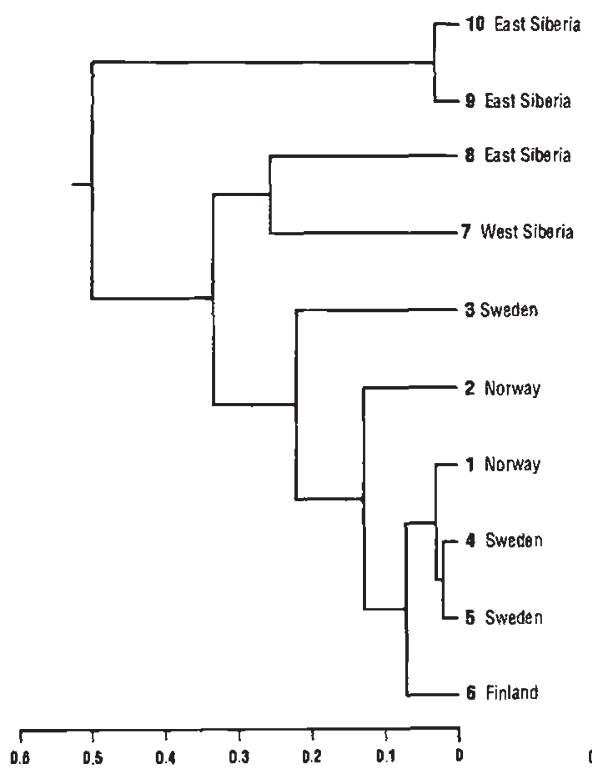

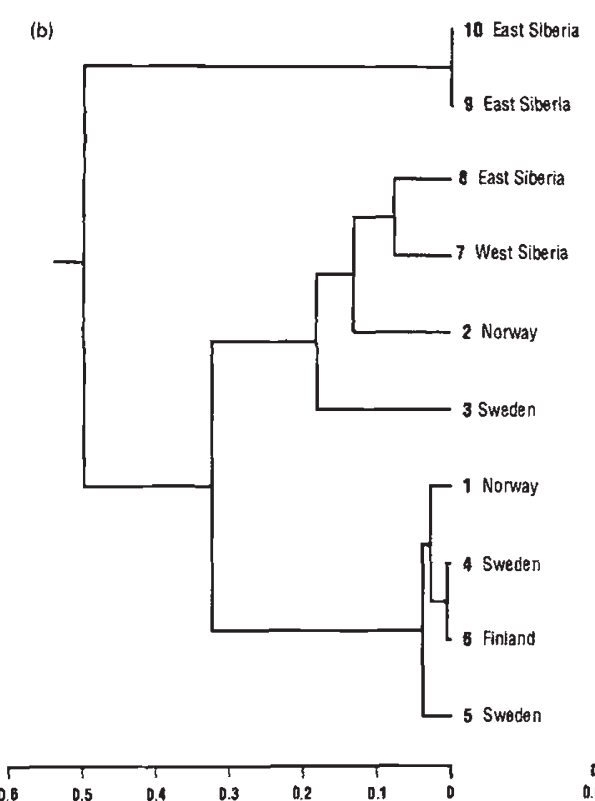
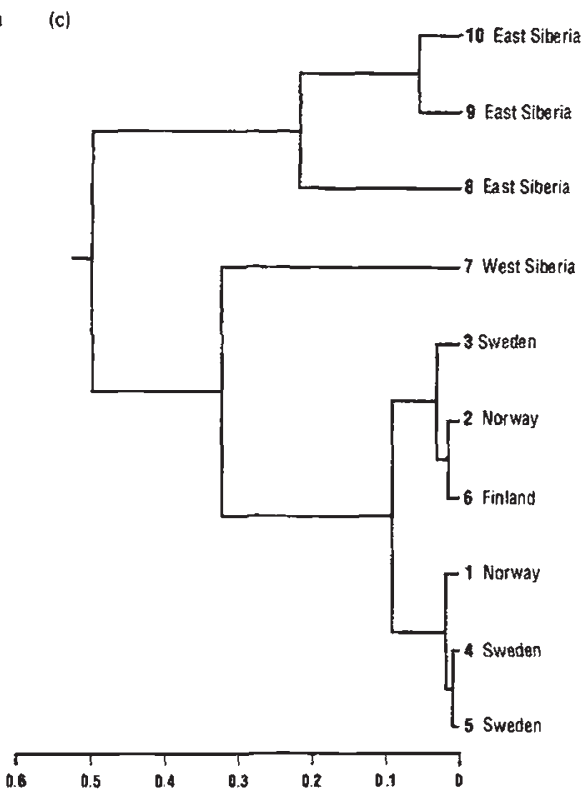

Fig. 2 UPGMA dendrograms of the populations based on Rogers's genetic distance calculated for: (a) Idh-I and Pgi-1; (b) Idh-1; (c) Pgi-1.

\section{Discussion}

According to theory, mutation, genetic drift and natural selection favouring adaptations to local environmental conditions will all lead to the genetic differentiation of local populations, and gene flow will oppose that differentiation (Slatkin, 1987). Genetic drift affects all loci in the same way, but natural selection does not (Slatkin, 1987). When the estimate of genetic subdivision at one locus differs considerably from the estimate at others, there is reason to suggest that it, or a locus linked to it, is subject to natural selection.
There is significant genetic differentiation among geographical populations of the wood lemming. Despite the similarity in total single-locus estimates of allele frequency variance, allele frequencies at $I d h-1$ and Pgi-1 demonstrate different patterns of macrogeographical subdivision. This probably means that the patterns are largely determined by different factors. The availability of only two polymorphic loci in the wood lemming makes it difficult to perform an analysis based on interlocus comparisons. However, the singlegene approach gives some evidence to suggest which factors may be responsible for the pattern of differentiation at each locus. 
On a macrogeographical scale the estimate of differentiation at $I d h-1$ increases with increasing hierarchical level, but genetic affinity does not reflect geographical location. Based on these observations, we suggest that differentiation among populations at the $I d h-1$ locus may result from genetic drift. If this is so, genetic dissimilarity between populations could be increased by physical barriers to migration. The two Southern Jakutia populations (9 and 10) clearly differ from the other East Siberian population, Chara (8), by having allele $I d h-1(100)$ fixed. Indeed, the Stanovoi mountain range, separating Southern Jakutia and Chara, must limit gene flow to a large extent. Additionally, the estimates of genetic subdivision among wood lemming populations at $I d h-1$ resemble $F_{\mathrm{ST}}$ values detected for other rodent species (Wright, 1978; Chesser, 1983; Navajias-Navarro \& Britton-Davidian, 1989; Patton \& Smith, 1990).

In contrast to the $I d h-1$ patterns, populations within each geographical region demonstrate homogeneity of the Pgi-I allele frequencies while every region represents a unique allele combination. The lack of population differentiation within regions appears to be quite unusual since populations of other rodents demonstrate significant differentiation in allele frequencies over similar geographical ranges (Wright, 1978), corresponding to the $I d h-1$ pattern in our study. There are two possible explanations for the differences between the patterns of geographical differentiation for each locus. First, it may be that the different patterns shown by $I d h-1$ and $P g i-1$ are due to stochastic changes in past history. This explanation could be sufficient to explain differences in the pattern of differentiation at each locus among geographical regions but it seems less likely to explain differences in the patterns at each locus within regions.

Second, the discrepancy between single-locus patterns may indicate the presence of differential disturbing forces such as selection (Weir, 1990). There is no evidence suggesting that selection acts on the $I d h$ 1 locus; $F_{\mathrm{ST}}$ values resemble those of other rodent species using other loci (Wright, 1978; Chesser, 1983; Navajias-Navarro \& Britton-Davidian, 1989; Patton \& Smith, 1990). Furthermore, an assumption of selection at $I d h-I$ would not explain the lack of polymorphism at this locus observed in two populations (9 and 10). The more plausible explanation for the difference between single-locus patterns is that selection probably acts on the Pgi-1 locus.

It seems reasonable to assume that selection favouring different alleles at the Pgi-1 locus in different geographical regions could be important in generating homogeneity among populations within regions and differentiation between regions. We also consider it possible that there is a longitudinal cline in allele frequencies at the Pgi-1 locus, but the number of regions is too small to show a reliable clinal pattern.

Since PGI is involved in an intermediary step in glycolysis, variation at the Pgi-1 locus may reflect environmental variation. Some evidence for selection acting on the Pgi-1 locus has already been found in the Western Siberian population (7) (Fedorov, 1993). A very great increase in Pgi-1 (111) allele frequency was observed over winter within one wood lemming generation. The most likely explanation for this observation was differences in fitness among various Pgi-1 genotypes during the winter.

There is an increase in the number of studies which indicate that natural selection acts on PGI in different species (Riddoch, 1993). It must be noted that all the examples of the selective significance of PGI were detected for poikilotherms. Metabolism of mammals depends to a lesser extent on environmental conditions. However, for another glycolytic enzyme (PGM), fitness differences among various genotypes in winter conditions were found in the wood mouse, Apodemus sylvaticus (Leigh Brown, 1977).

The results of our study represent an unusual pattern of macrogeographical differentiation at Pgi-1 in the wood lemming. At a macrogeographical scale the discrepancy between single-locus patterns of subdivision seems likely to result from selection at the Pgi-1 locus, and there is some indirect evidence mentioned above suggesting that Pgi-1 variation is maintained by fluctuating selection (Fedorov, 1993). However, the selective agents generating the observed pattern of variation at the Pgi-1 locus remain obscure. Even if geographical patterns do result from genotypic adaptation to different environments, the demonstration of fitness differences based on kinetic properties of allozymes is difficult to interpret (Hartl \& Clark, 1989). It would be more revealing to determine the significance of geographical Pgi-1 variation through its comparison with variation using other types of polymorphic genetic markers, such as DNA markers. Our hypothesis predicts the existence of statistically significant differentiation between populations within every geographical region for selectively neutral DNA markers.

\section{Acknowledgements}

We thank both Pekka Pamilo and Robert Paxton for valuable comments on this paper; and Asko Kaikusalo for providing us with wood lemmings from Finland. This work was supported by grants to V.F. from the International Science Foundation; to R.F. from the Nilsson-Ehle foundation; and to K.F. from the Swedish Natural Science Research Council. V.F.'s stay in 
Sweden was supported by a scholarship to K.F. from the Swedish Institute.

\section{References}

BONDRUP-NIELSEN, S., IMS, R. A., FREDRIKSSON, R. AND FREDGA, K. 1993. Demography of the wood lemming, Myopus schisticolor. In: Stenseth, N. C. and Ims, R. A. (eds) The Biology of Lemmings, pp. 493-507. Academic Press, London.

CHESSER, R. G. 1983. Genetic variability within and among populations of the black-tailed prairie dog. Evolution, 37, 320-331.

FEDOROV, v. B. 1990. Allozyme polymorphism in a natural population of wood lemmings (Myopus schisticolor Lill.). Genetika, 26, 1324-1328. (In Russian).

FEDOROV, v. B. 1993. Genetic variation in the wood lemming Myopus schisticolor. Ecologya, 1, 70-82. (In Russian).

Felsenstein, J. 1993. Phylip (Phylogeny Inference Package) version $3.5 \mathrm{p}$. Distributed by the author. Department of Genetics, University of Washington, Seattle.

FREDGA, K., GROPP, A., WINKING, H. AND FRANK, F. 1976. Fertile $\mathrm{XX}$ - and XY-type females in the wood lemming, Myopus schisticolor. Nature, 261, 225-227.

FREDGA, K., GROPP, A., WINKING, H. AND FRANK, F, 1977. A hypothesis explaining the exceptional sex ratio in the wood lemming (Myopus schisticolor). Hereditas, 85, 101-104.

FREDGA, K., FREDRIKSSON, R., BONDRUP-NIELSEN, S. AND IMS, R. A. 1993. Sex ratio, chromosomes and isozymes in natural populations of the wood lemming, Myopus schisticolor. In: Stenseth, N. C. and Ims, R. A. (eds) The Biology of Lemmings, pp. 465-491. Academic Press, London.

GILEVA, E. A. AND FEDorov, v. B. 1991. Sex ratio, XY females and absence of inbreeding in a population of the Wood Lemming, Myopus schisticolor Lilljeborg, 1844. Heredity, 66, 351-356.

GORBUNOV, S. M. AND KULIK, I. L. 1974. Cadastre-information map of the wood lemming, Myopus schisticolor, range. Zoologiceskij Zurnal, 53, 144-146. (In Russian).

HARTL, D. L. AND ClARK, A. G. 1989. Principles of Population Genetics, 2nd edn. Sinauer, Sunderland, MA.
LEIGH BROWN, A. J. 1977. Genetic changes in a population of field mice (Apodemus sylvaticus) during one winter. $J$. Zool., 182, 281-289.

MANLY, B. F. J. 1991. Randomization and Monte Carlo Methods in Biology. Chapman \& Hall, London.

McELROY, D., MORAN, P., BERMINGHAM, E. AND KORNFIED, I. 1992. REAP: an integrated environment for the manipulation and phylogenetic analysis of restriction data. J. Hered., 83, $157-158$

NAVAJAS-NAVARRO, M. AND BRITTON-DAVIDIAN, J. 1989. Genetic structure of insular Mediterranean populations of the house mouse. Biol. J. Linn. Soc., 36, 377-399.

PAMILO, P., PEKKARIEN, A. AND VARVIO, s. L. 1987. Clustering of bumble bee subgenera based on interspecific genetic relationships (Hymenoptera, Apidae: Bombus and Psithyrus). Ann. Zoo. Fenn., 24, 19-27.

PATTON, J. L. AND SMITH, F. S. 1990. The evolutionary dynamics of the pocket gopher Thomomys bottae, with emphasis on California populations. Univ. Calif. Publ. in Zool., 123, $1-149$.

RIDDoch, B. J. 1993. The adaptive significance of electrophoretic mobility in phosphoglucose isomerase (PGI). Biol. J. Linn. Soc., 50, 1-17.

ROGERS, J. S. 1972. Measures of genetic similarity and genetic distance. Studies in Genet. VII. Univ. Texas Publ., 7213, 145-153.

ROFF, D. A. AND BENTZEN, P. 1989. The statistical analysis of mitochondrial DNA polymorphism: $\chi^{2}$ and the problem of small samples. Mol. Biol. Evol., 6, 539-545.

ROHLF, F. G. 1988. NTSYs-pc: Numerical Taxonomy and Multivariate Analysis System. Exter Publishing Ltd, New York.

SLATKIN, M. 1987. Gene flow and the geographic structure of natural populations. Science, 236, 787-792.

SWOFFORD, D. L. AND SELANDER, R. B. 1981. A computer program for the analysis of allelic variation in genetics. $J$. Hered., 72, 281-283.

WEIR, B. S. 1990 . Intraspecific differentiation. In: Hillis, D. M. and Moritz, C. (eds) Molecular Systematics, pp. 373-410. Sinauer, Sunderland, MA.

WRIGHT, s. 1978. Evolution and Genetics of Populations, vol. 4. Variability Within and Among Natural Populations. University of Chicago Press, Chicago. 